\title{
Trust in Virtual Teams: A Performance Indicator
}

\author{
Marina Keiko Nakayama ${ }^{1}$, Erlaine Binotto ${ }^{2}$, and Bianca Smith Pilla ${ }^{3}$ \\ 1 Universidade Federal do Rio Grande do Sul, Brazil \\ 2 Universidade do Planalto Catarinense, UNIPLAC, Brazil 1 \\ 3 Universidade Federal do Rio Grande do Sul, Brazil
}

\begin{abstract}
This paper aims to analyze how virtual teams deal with the process of trust among the people who are part of it. The research is characterized as descriptive. The survey data techniques that were used were questionnaires via Internet and interviews by telephone. The participants of this research were eight managers from Embratel, a telecommunication company in Brazil. The results of this research pointed out that, for its participants, trust is a significant performance indicator for the collaborators and that reciprocity, positive expectation and foresight are base concepts so that all may feel secure when it comes to the risk of a negative consequence and vulnerability. The clear definition of the objectives, the emphasis in internal communication, the manager as an example and model, and the worthiness of the people become the main care and practice in order to obtain better trust in virtual teams.
\end{abstract}

\section{Introduction}

Virtual teams are groups of people whose work is inter-related. Despite the fact that they perform their activities geographically apart, they portray the present-day moment marked by the adaptation of available technology and administrative concepts to all scattered teams. This is present day reality since increased speed forms a competitive advantage to an organization. He who works with teams realizes that, to compensate for the fact that they work apart, the placement of some rules is important in order to be efficient. It is essential for the group to have the scope of the work clearly defined, through the necessity of vision, the mission and team objectives, comprehending what is each and everyone's contribution by the end of the job. Besides the resources, qualification, and structure for teamwork, the trust relation was one of the most contemplated variables when we developed our research with virtual teams [1].

Trust in organizations is something that operates simultaneously in different levels between the high administration, leaders, present or virtual working teams, 
collaborators, commercial partnerships, etc. Kelley [2] makes a comment on the success of global virtual teams that is specifically focused on inter-relations based and built on trust and partaking something that inefficient teams do not have.

Cufaude [3] states that the issue on trust has been discussed by many authors, mainly in the organizational area, due to the importance of this concept as an essential element of work. When it comes to organizational environment, there is a lack of completeness of the concept that people have in mind concerning trust, the conditions that make a trust relation hard or easy, the practice of virtual teams to win and maintain trust at work, and on how the lack of trust may interfere in the process and results. The emphasis in this study is to understand the different approaches by authors that deal with the subject and comprehend in a practical sense how a trust relation occurs in a team.

The issue here is: how do virtual teams deal with the trust process among those who take part in it? Thus, the objective is to analyze how virtual teams handle the trust process among themselves. The specific aims are: identify people's concepts on trust in virtual teams in the organizational environment; verify what are the conditions (dimensions) that ease or make difficult the trust relation in virtual teams and what are the cares and practices that the people and the leader adopt in order to gain and maintain trust; identify what is missing in the ambience among the people to improve and attain good results when it comes to reliability that can increase team productivity; and verify the lack of trust or a problem that might reduce trust and on how it may interfere in behavior in the virtual teams process of work.

\section{Theoretic Reviews}

\subsection{Defining Trust}

Research on updated literature lead to several authors who find interest in the trust concept as in a relevant factor in the intra and inter-working teams relationship. The foregoing definitions on trust imply three basic concepts: 1) vulnerability [4], 2) reciprocity [5], and 3) expectation [6]. Commencing from this research, trust may be defined as a disposition to diminish vulnerability in a team based on positive expectation as a result of mutual positive interactions in the past. This definition reflects on the three basic concepts of trust and the dynamic ambit of the trust cycle as well. To be vulnerable means the possibility of impairment and potentially face negative results [7].

Trust, as a concept, is the point where several organizational research disciplines inter-relate. Despite the great quantity of research on trust by scholars, there is no definition that gathers all the ideas about it [8] [9] [10]. Different areas, such as inter-organizational and interpersonal, have different operations of trust as the object differs [10].

According to Zand [5], trust is related to actions that increase vulnerability to one another. Trust behavior, therefore, involves the growth of someone's vulnerability to others whose behavior cannot be controlled. This apparently guarantees to 
organizations and/or individuals that they may indeed take similar risks in exchange [11].

In the organizational context, as situations become more complex, vulnerability to the authors becomes more common and predominant, given the increasing incapacity to foresee action [12]. It appears to be that trust is intimately tied to a future indefiniteness as long as this indefiniteness is human and not purely out of natural origin. Nevertheless, the trust behavior that involves disposition of taking risks is not a risk factor of its own as demonstrated by a person who plays in a casino with his likely knowledge and probabilities. On the contrary, trust behavior contains more than that: there is not always knowledge on probabilities, and vulnerability is at stake.

Another necessary condition on trust is the incapacity to monitor and control a team member's behavior due to inaccessibility [5] [9]. The interdependence of a situation on trust points out the importance of a positive and mutual interaction among confidant people. For this reason, reciprocity rules have a great importance in trust behavior and are additional characteristics that are common in it [5] [8] [11] [13]. When we speak of reciprocity rules, we mean a positive interaction case between teams and not only a foregoing experience as an object of trust [8]. The positive mutual interactions among these authors conduct to another mutual dimension of trust: expectation throughout time.

Expectation throughout time is a key factor in various definitions on trust [14]. Lewicki, McAllister and Bies [14] defined trust as positive and trustful expectations concerning each other's conduct. They use the term conduct of each other in a generalized expectation that a word, promise, written or verbal declaration of another individual or group may be trusted. The result of the expectation of another team brings up a central element in the definition of trust by Mayer, Davis and Schoorman [9]. They suggest that the disposition to take a risk is based on the expectation that the other team will fulfill a specific action to which it is trusted [9]. For most theorists, trust includes an expectation in relation to the other's reaction [15] and this expectation is naturally the awaited answer [6].

To trust, when it comes to behavior and emotion, is to have positive and reliable expectations and act as if the uncertain future acts by the others are for granted. The violation of these expectations results in negative consequences to those involved [8] [14].

The comprehended probability of loss, for example, when acknowledged by a decision-maker, is a key factor in trust behavior [16]. This highlights an indisputable historical knowledge that exalts positive expectations upon the team. A good collection of specialized books also raises the importance of positive interaction among teams, which increases reliance [5] [11]. Finally the research links interpersonal and behavioral history with changes on reliability.

\subsection{Virtual Teams}

Trust here is treated like a dimension of organizational interrelations. However, it can be said that in virtual teams these are interposed to peculiarities as innovating as technology that it gives support and implicates to think over specifications. The 
relationship environment can exist at any time and any place and among people of any part of the world. All that is necessary is that this "meeting" becomes mediated through technological resources (computers, telephone, etc.) to promote the virtual contact. However, such function with "no boundaries" attested in terms of time and space (physical environment) demands some limits that refer to the human interrelation aspect.

Zimmer [17] defined virtual teams as working groups formed by people who interact by distance in a permanent or temporary way. Proceeding from a company and/or net, by using advanced technology to maintain contact or carryout tasks they aim to achieve common purposes.

Some authors, such as Lau, Sarker and Sahay [18], indicate that the accomplishment in virtual team communication is related to social and technological aspects that complete the Social and Task dimensions. The Social Dimension refers to the personal ambit interposed by attributes of relationships that will support communication between team members. The Task Dimension involves efficiency of communication in the framework of actions and in the interchange of information for the accomplishment of terms and goals.

\subsection{Relationship between Virtual Teams and Trust}

Trust may contribute in the discussion about virtual teams, but exactly what kind of trust are we talking about here? In a first understanding, it is a personal characteristic, an attribute attached to education that comes a long way from an individual's personal development. This kind of trust takes a while to reach the surface and requires care to be maintained. Here we refer to the organizational environment where it is not always possible to have a long period of time to initiate a project. Also, there are possibilities such as people entering the group in the middle of the process. There is also the chance of working with people that make it impossible to get to know better as in most virtual team cases.

In an interrelationship mediated in a virtual way, the control over actions of another is even more difficult than among "real" team members. Expectation by reciprocity is great and relative frustrations to such expectation may occur. Repeated frustrations might cause fragile interrelationships among the teams and lead to encumbrance in the execution of tasks and objectives. Such consequences occur due to fear of facing new situations of failure. Thus, the promotion of trust among virtual team members has a fundamental role. According to Tzafrir and Harel [7], the probability of failure, when taken by a decision-maker, is a crucial element in trust behavior. This requires a "positive history" from all parts, which elevates positive expectations over another team. Specialized literature hints at the importance of positive interaction among teams to increase and reinforce trust [5] [11], which promotes performance improvements in these teams.

According to the literature, it is pertinent the approximation of the concept on trust to contribute in the discussion on interrelationships in virtual teams and the probability to assert the role of confidence as a significant performance indicator. Trust, as presented in [7], implies disposition in diminishing the vulnerability in the involved teams. That is, trust promotes a better power of resistance to possible 
frustrations, taking as base positive expectations of a team over another. Such expectations, finally, are based on positive experiences in the past in the interaction of teams.

\section{Methodological Procedures}

The developed research is characterized as descriptive. The survey techniques of data were questionnaires via Internet and interviews by telephone. Access to the interviewees was facilitated by the fact that one of the managers was already familiar with the researchers and accepted to participate, stimulating others to do the same. The research, from July to October of 2004, was held at Embratel, a company that offers solutions in the telephone business besides data and Internet. The participants were a total of eight managers, all between 37 and 52, among technicians and engineers. Research data analysis was interpretative.

\section{Result Discussions and Analysis}

For the result analysis, specific established objectives at work should be regarded.

Concepts that people who are involved with virtual teams have concerning trust in organizational environments and that trust can be considered as a performance indicator:

The research participants regard trust as a significant performance indicator for the team and attest aspects like: all energy and time will be invested in search for results; indispensable to maximize performance; energy becomes concentrated for the final objective contributing to improve the organization's fulfillment; interpersonal and inter-group trust as an essential performance indicator for the organization despite difficulties in evaluation; and without it each member's energy increases, thus diminishing efficiency.

The concepts of some participants involved sharing and reciprocity. Others indicated the foresight of actions referring to earlier situations. These concepts affirm the definitions by Zand [5] concerning reciprocity as a base concept for trust. Expectation has been mentioned by several authors like Lewis and Weigert [8]; Mayer, Davis, and Schoorman [9]; Lewicki and Bunker [6]; Lewicki, McAllister and Bies [14]; and Bhattacharya, Devinney and Pillutla [15].

Conditions that facilitate the trust relationship among people that form part of the virtual team in an organizational environment:

All participants mentioned competence and/or knowledge and technical ability as conditions to facilitate trust. Mayer, Davis and Schoorman [9] reinforce the ideas that trust behavior deals with the capacity of the team to be trusted. Cook and Wall [19] and Buttler [11] equally affirm that competence, power, ability and knowledge to do what must be done in an adequate and sufficient way will incrust security and trust in mutual relations.

Loyalty was the second most mentioned condition: it is fundamental that people should be honest and grab hold of loyalty values defined by the team; 
comprehension, dedication, faith in their missions, values, and objectives in the group within the society. Loyalty is a disposition to protect and defend another person. Trust requires that you believe that the person will not be an opportunist. The participants, in this case, refer mostly on values in a team and the organization. Zucker [13] brings up base expectations to define a similar construction. Mayer, Davis and Schoorman [9] identified similar characteristics of harmony among his reliability factors. It was stated how important it was for a team to adhere to an assemblage of principles that he who trusts finds it acceptable in order to build-up trust. Harmony indicates acknowledgement, adhesion and acceptability. Disposition to take risks, in harmonic situations, increases dramatically as well as trust in positive expectations.

The third condition recalled by the researchers was on how receptive people are for compliments and criticism as well in daily situations. This makes growth possible and generates learning. Other conditions were: ease of communication, desire to help, contention, patience, emotion, power of criticism, and analysis to react with intelligence and creativity in administrative situations. Just the fact that the person works in a company is enough to believe in his own competence, loyalty, etc., and consequently in the result that the group will achieve and the compromise.

Conditions that make the trust relationship between those who are part of a virtual team hard in an organizational environment:

The participants, in general, do not explicitly express what is wrong in a trust relationship between people. One may conclude that the lack of the described conditions that ease things off may make it harder. That is, lack of competence and loyalty. One manager said that what sometimes might happen to make trust harder is mainly related to lack of accessibility to some people.

Care and practice by the leader and people in order to gain and maintain trust:

The participants show consciousness when it comes to the need to maintain the scope of work clearly defined. This includes the necessity of vision, the mission and objectives to be team domain, understanding each and everyone's contribution in the final result

Other concerns emphasize internal communication: sharing info; show concern with one another; trust behavior maintenance and group acceptance; establish and let be known the values that lead to the actions; realize and encourage the actions that reinforce common values; share positive and negative views for the future with the team; recognition of achieved results and word that all the people are important for the organization and, more than that, they are responsible for the good or bad result of work; maintain clear channels of communication.

Practice and care contemplate the evaluation of each other and the example of the leader: evaluation of the many members of the team and their competence; intense use of the practice of the delegation of the attributes and maintenance of informal environment and sense of union; act and think with honesty based on principals; be an example and take care so that the formal and informal process of communication respects the people and their differences; show respect to abilities and peoples knowledge; make sure that the action is coherent with the discourse; when deciding upon occurrences, till you can prove the contrary, act admitting that the other person acted accordingly. For the leader to maintain confidence, he must be consistent and be an example, fulfill promises and share future sights with both positive and 
negative aspects with the team. There is still the incentive in participation, recognizing the original source of ideas and/or true effect of certain feats; eliminate dishonest members in a team through autonomy and the delegation of decisions. These results complete the affirmatives by Kelley [2] that a virtual team's success is focused on interrelations based and built on trust and sharing, which is the differential upon teams that do not.

What is missing in an environment among people to improve and attain better results when it comes to trust that can meliorate the team's productivity:

Some consider that individual attitude is an obstacle for the improvement of team results. Aspects such as too much concern with one's self are detrimental to the group. Personal vanity and unmeasured ambition are a hindrance in the establishment and cultivation of a reliable behavior in the ambit of a team.

Others say that there is a lack of time for people to get to know each other better. It becomes an obstacle to productivity. One manager mentioned the need of events for such purposes. Even if the team is virtual, they could have a chance to make direct contact by meetings, courses, parties, etc., and attain a greater bond of trust. Direct visual contact, most typical of human senses, is indeed important. Another is the lack of knowledge concerning the executed task by another person, including lack of information and accessibility.

Lack of trust or a problem that weakens trust and interferes in the people's behavior at work in virtual teams:

The question had the intention to verify the lack of confidence among the people in teams or a problem that reduces trust or interferes in the behavior of people in the process of work in virtual teams. The participants, in a general sense, understood what factors were generated by trust and observed aspects such as doubt in people's minds, questions and thoughts that increase preoccupation at an additional cost of energy under supervision. This is enough to make items of verification and additional controls. One said that the lack of trust or a problem that causes it interferes with our behavior causing longer cycles to execute activities (standard process); demand of greater formal relationship, sometime through writing; interruption on normal flux to evaluate the exchange process. There is a reduction in sharing knowledge and information, a waste of energy that does not result in increased volume of production nor in better quality production. In truth this fact lifts up defense barriers and brings forth isolation. It was also stated that dynamism and fluidity that should exist gives way to resistance and defense in a way that if more members break down in trust, group quality falls and mission, values and objectives of the organization end up in poor standing with the customers. Lack of trust causes the energy wasted by each member to increase. When there is trust, the tasks are better distributed, the necessity of control (check-list) is smaller, and the action procedures are more internalized and integrated. This factor is determined for success at work in virtual teams. 


\section{Final Considerations}

This work was an opportunity to analyze how a virtual team deals with trust among those who make up a group.

The participants of this research make it clear that they consider trust as a significant performance indicator and that reciprocity, positive expectation and foresight are base concepts that make the participants feel secure about the risk, negative consequences and vulnerability.

They relate interpersonal and technical competence, loyalty and receptiveness as important conditions to facilitate trust relation among people. Competence is defined in the sense of capacity, abilities, technical and interpersonal knowledge of the individual. Loyalty refers to agreement, adherence, and the acceptability of values of the team and the organization. Receptiveness is related, in this case, to be open to receive criticism and praise. They also consider that the lack of mentioned conditions harden a trust relation.

The main care and practice regarded by the participants are related to clear definition of goals, emphasis on internal communication, spread out, repeat and communication (formal and informal) of the objectives, values and aims of the group, and being an example and model giving people rightful value.

The participants believe that an emphasis on individual thought may impede improvement in productivity in the group. All agree with the abrading results of lack of trust that may occur among people in the group.

With these results the suggestions are:

Adopt trust by involving base concepts (reciprocity, positive expectation and foresight) as the team's performance indicator;

Talk with the team about their values and that of the organization with the intention to verify if people are understanding each other the same way;

Check on how each person deals with receptivity in order to accept criticism and praise, and to qualify people to give and receive individual feedback in a group;

Adopt a system that may accompany and verify that all participants are understanding the objectives of each process;

Adopt a system to determine people's perception in relation to the evaluation of the collective results and each one's role in the final result.

Work brings a subsidy so that the team may perfect their performance and reflect upon their behavior individually in a team.

\section{References}

1. Nakayama, M.K. and M.A.M. Matoso, Virtual teams performance: an analysis based on indicators, International Association for Development of the Information Society Conference: e-society, v. 1, p. 387-391, Lisboa (Portugal), 2003.

2. Kelley, E, Keys to effective virtual global teams, The Academy of Management Executive, Pennsylvania, v. 15, n. 2, p. 132-133, May 2001.

3. Cufaude, J., Creating organizational trust: elusive. Fragile. Essential. Association Management, Washington, p. 26-34, July 1999. 
4. Curral, S. C. and T.A. Judge, Measuring trust between organizational boundary role persons, Organizational Behavior and Human Decision Processes, New York, London, Academic Press, 64(2), November, p. 151-170, 1995.

5. Zand, D.E, Trust and managerial problem solving, Administrative Science Quarterly, Ithaca, 17(2), p. 229-239, 1972.

6. Lewicki, R.J. and B.B. Bunker, Developing and maintaining trust in work relationships, In Kramer, M. R.and R.T. Tyler (eds.), Trust in organizations: frontiers of theory and research, Thousand Oaks, CA: Sage, 1996. p. 114-139.

7. Tzafrir, S.S. and G.H. Harel, Confie em MIM: uma escala para medir confiabilidade empresária - empregado, Congresso de Haifa, IEEE Mediterranean Conference on Control and Automation, July 9-12, 2002.

8. Lewis, J.D. and A. Weigert, Trust as a social reality, Social Forces, Chapel Hill, N.C.: University of North Carolina Press, 63, p. 967-985, 1985.

9. Mayer, R.C., J.H. Davis, and D.F. Schoorman, An integrative model of organizational trust, Academy of Management Review, Ohio, 20(3), p. 709-734, 1995.

10. Rousseau, D.M., S.B. Sitkin, R.S. Burt and C. Camerer, Not so different after all: a crossdiscipline view of trust, Academy of Management Review, Ohio, 23(3), p. 393-404, 1998.

11. Buttler, K.J. Jr, Reciprocity of trust between professionals and their secretaries, Psychological Reports, Missoula, Mont, 53, p. 411-416, 1983.

12. Bigley, G. A. and J.L. Pearce, Straining for shared meaning in organization science: problems of trust e distrust, Academy of Management Review, Ohio, 23(3), p. 405-421, 1998.

13. Zucker, L.G, Production of trust: institutional sources of economic structure, $1840-$ 1920. Research in Organizational Behavior, Greenwich, Conn.: JAI Press, 8, p. 53-111, 1986.

14. Lewicki, R.J., D.J. Mcallister and R.J. Bies, Trust and distrust: new relationship and realities. Academy of Management Review, Ohio, 23(3), p. 438-458, 1998.

15. Bhattacharya, R., T.M. Devinney, M.M. Pilluta, A formal model of trust based on outcomes, Academy of Management Review, Ohio, 23(3), p. 459-472, 1998.

16. Chiles, T.H. and J.F. McMackin, Integrating variable risk preferences, trust, and transaction cost economics, Academy of Management Review, Ohio, v. 21, n. 1, p. 73-99, 1996.

17. Zimmer, M.V., A criacao de conhecimento em equipes virtuais: um estudo de caso em empresa do setor de alta tecnologia, 2001. Dissertação (Mestrado em Administração) Programa de Pós-Graduação em Administração, Escola de Administração, Universidade Federal do Rio Grande do Sul, Porto Alegre, 2001.

18. Lau, F., s. Sarker and S. Sahay, On managing virtual teams, Disponível em: $<$ http://www.bus.ualberta.ca/flau/Papers/cacm.htm $>$. Acesso em: 10 mar. 1999.

19. Cook, J. and T. Wall, Organizational commitment, In Cook, J., S. Hepworth, T. Wall, and R. Warr (Eds.), The experience of work, New York, Academic Press, 1980. p. 91-93. 